\title{
Significance of Sharing Information using Websites for Educational Institutions in Pakistan
}

\author{
Muhammad Kamran Jamil and Syed Asad Hussain \\ SZABIST \\ Karachi, Pakistan
}

\begin{abstract}
:
Technology is now a key factor in driving the economies of the world. Whether $\boldsymbol{i}$ is the field of pure or medical sciences; management or social science; technology's involvement and influence is there. Technology and its fast adoption have not only changed the traditional way of doing businesses but also directly affected the individual personalities, societies and nations. It has increased the efficiency, horizon the span of knowledge and strengthened the medium of information seeking. Websites being an essential tool of information technology have affected all industries. As web technology facilitates information and knowledge sharing therefore very much relevant and most applicable to educational institutions. Educational institutions use websites to share information with prospective students, existing students, researcher and else whosoever is interested to know about the institution. Likewise website of other organizations where organizations try to promote and introduce their product and services, educational websites also make efforts to transfer institution's related information to the public specially those mentioned above. As Information Technology has changed the way of doing business, similarly, it has changed the traditional way of seeking knowledge. Unlimited educational information is available through Internet, which does not only facilitate students and researchers to get online information but also help them to share information and views across the borders. With the innovation of Internet technology and its wide usage, there is no physical barrier to information and knowledge. Due to removal of this barrier organizations' emphasis towards hiring and employing "knowledge workers" has been increased.
\end{abstract}

\section{INTRODUCTION}

Information in today's competitive world is the key measure for success. Information helps organizations in planning, organizing, staffing, controlling and decision making. Fast, reliable, accurate and precise access to information ensures competitive edge in the business operations.

Explosion of Information Technology (IT) has led to the development Information Systems Management and hence changed the traditional management practices. Information Systems and Database Management Systems facilitate speedily processing, fast accesses to data, vast storage, reliable and consistent retrieval and hence improved decision making, planning and implementation process.
Traditionally, information movement was slow and unreliable in the context of its significance and urgency. Information was sent through a sender's reliable medium cannot assure effective delivery by the receiver. It was not said with assurance that how much time will it take to reach an information and what constraints will be faced by the medium through which the messages were sent. With the improvement in transformation of information, the significance progress has been made in improving the medium through which messages were sent. The revolution has taken place from personal human delivery to now electronic communication where the messages are sent are received by the recipient within not time.

To remain competitive in the global environment, one has to be conformant with the latest IS Management practices. Fast access to information and capitalizing the opportunity through quick decision-making are the keys to success. Today's organizations are turning their operations towards computerization to achieve effectiveness and efficiency in order to cater larger market share. Use of Information Systems is becoming common in large local and multinational organizations in Pakistan but most of the medium and small enterprises are still ignorant with the use and application of Information Systems. [1]

Information systems are designed in any organization for the following reasons:

- The internal and external customers of the organizational processes

- The products/services generated by the organization's processes

- The steps involved in performing list of activities

- The participants in the organizational processes

- The information that organization's process uses or creates

- The technology that organization's process uses

In any organization, operations framework consisting of following elements:

- Business processes - activities performed in an organizational environment

- Participants - involved in business processes

- Information - knowledge participants share while performing the tasks

- Information Technology - tools used to share information

The information system is therefore the part of the system that happens to use information and information 
technology. Adopting this viewpoint helps in resisting the tendency to analyze information system as purely technical systems without regard to why they exist. The tendency is probably one of several key reasons for the ineffectiveness of many information technology applications. [2]

Information system in education industry is as important as database management of customers and sales in other industry. IS in Education industry facilitates following:

- in developing procedures for admission process/intake

- in maintaining students' record and their registration/enrollment status

- $\quad$ in locating/accessing relevant books through Library Information Systems

- $\quad$ in keeping students' accounts ledger up to date

- in establishing educational information (transfer/exchange) network through www

- in ensuring vigilant examination process

- in bringing out quick and reliable transcripts/statement of marks

- in communicating students globally

- in accessing institutions' information to remote areas

Further, there are systems similar to that of other industry like,

- computerized system for educational staff working in that institution

- maintaining payroll and accounting/financial modules/system

- inventory or stocking system

- procurement and purchasing

- general security system

- office automation

It is commonly perceived that IS in the education industry is not as important as in the other industries. As a matter of fact implementation of Information Systems in education industry has not only improved practices of educational administration but also has direct impact on the quality intake of students. The availability of institution's educational information, sharing of information, access to well-stocked libraries of the world, over the web has made knowledge 24-hour learning resource center. It facilitates students to select the courses, register in the new semesters and access to their results remotely. No matter whatever the complexities or difficulties, in order to operate smooth functioning of educational administration, implementation of IS in the education sector is must. [1]

Wide spread of Internet and its common use made it compulsory for every business and educational institute to use this technology. The World Wide Web (WWW) "is a set of interconnected electronic documents, called web pages that are linked together over the Internet". The Web is the fastest growing part of the Internet. For many people, the Web is the Internet, for that is the only part of the Net they use. Websites on one side provide information to those interested in your service or product and on the other hand sometimes become the only source for customer contact from information seeking to purchase of product or avail of services. Like Amazon.com and other product and service offering companies through websites where customers have never visited but seems satisfy with the service they are offering. The question arises that how we can achieve satisfaction without physically visiting the seller's shop or personally chatting with them? But the universal authenticated and reliable presence of websites made it possible. There are thousands of educational institutions especially in the developed countries which have their own websites where they maintain data both for existing and prospective students. [3]

\section{EDUCATION INDUSTRY IN PAKISTAN}

Education sector of any country has direct impact on the progress and prosperity of the nation. It is among the core necessities and a condition for economic development. The Pakistan had not made any significant progress in the education sector in the past, and hence the literacy rate in Pakistan very low. Due to this low literacy we are far away from new technologies adopted by developed nations in order to simplify the work and bring efficiency. Pakistan is located at a strategic place where it may become hub for Middle East, Far Fast, Central Asia and European countries. We need reform in education sector from primary to higher level in order to survive in global competitive environment. It is now time to stand up for Change! There are hundred of questions raised in our minds about higher education and its prospects in Pakistan; Why public universities are not imparting quality education? What is the role of Higher Education Commission or is there any difference by changing name from UGC to HEC? Are any strategic reform policies for Education or it is only limited to the papers? Is there any control mechanism or accountability on the private universities? What is the criteria for setting up an institution and are those criteria are followed? Is there any liaison between the institutions and industry? and number of other questions which puts a big question to our educational system and to the officials made responsible for the promotion of education in our country.

A quick comparison would tell us that private universities are teaching courses for which there is a market demand. Their salary structure is flexible and helps attract top professionals in any given subject. The public universities on the other hand have some department that do not seem to have any understanding of changed needs of the job market. And if that was not bad enough, some of the public university teachers continue to provide obsolete information to students. Consequently, an increasing number of students continue to get higher education that is of little or no relevance. [4] Education Industry in Pakistan has brought revolution due to the entry of private sector. New and market-oriented programs have been introduced 
by private universities, which forced public universities to change their attitude if they want to survive. They have not only come up with the innovative programs but also brought in proper educational system. Traditionally, students were often put into academic administrative problems due to non-availability of Educational Information System. Students' data, attendance record, marks sheet and online information were not available. Students were required to spend much of their time in order to streamline their academic administrative matters. With the introduction and fast adoption of Information Technology it has now become possible to have such information available but still there are public universities who have not taken initiative towards computerization of their academic operations. [1]

\section{APPLICATION OF INFORMATION SYSTEM IN THE EDUCATION INDUSTRY}

It has been known that many education systems around the world face accumulating economic and other pressures, and are unable to meet the needs of increasingly knowledge-intensive economies. With the emergence of the Internet, database, there is potential to completely alter the landscape for commerce, education and social-cultural interaction. Whereas IT merely enhanced productivity or the control over information, the Internet is a fundamentally different technology that reshapes our social and economic relationships. The uncontrolled growth of information is flooding universities and learners alike with knowledge from all kinds of resources.

At the same time, increasing competitiveness and globalization is creating needs for learning that extend far beyond theoretical scope, such as the need for lifelong and open learning. The change in the conception of knowledge and needs for learning has been characterized as shifts in learning towards an more-oriented, distributed, masscustomized and multi-node learning, complex and adaptive paradigm.

Given these changes, universities have to fundamentally rethink their roles. Universities and their elements need to be re-conceptualized within a broader setting that shows how they can be shaped to the needs of knowledge-based societies. The notions that need to be revised foremost are the ideas that they are static, slowly changing entities, that they are less responsive to societal needs than to their own, and that students are essentially containers to which contents must be "delivered". [5]

Application of information systems in the education industry has become essential in order to coordinate and share information to facilitate students in their routine academic administrative issues. By deploying information systems in the academic operations will not only increase the overall efficiency but also allows institutions to focus on academics which is their core function. [1]
Information Systems in educational institutions can be classified into two systems i.e., core and supplement ISs, which are as follows:

\section{Core Educational Information Systems}

1. Students' Info. Systems (admission \& registration)

2. Result/Transcript Information Systems

3. Testing/Evaluation System

4. Library Information Systems

5. Web Information Systems (web site)

6. Graduate/Alumni Information Systems

Above systems are linked together to establish a comprehensive EIS and hence serve the purpose of handling all educational administrative issues.

\section{Supplement Educational Information Systems}

1. Human Resource Information System - HRIS (Faculty/Staff Information Systems)

2. Finance \& Accounting Information System - FIS (Payroll, cash flows, etc)

3. General Security Information System - GSIS

4. Office Automation (OA)

\section{Web Information System}

Web technology is nowadays a fast medium of communication. It facilitates fast transfer of data and information but at the same time also ensures its full reliability. Developing a website is neither costly nor its development requires heavy investment. It may be developed even without any cost through web hosting service providers on the net. With the increase in global competition and globalization, information is not remaining static. One has to be operative for 24-hour in order to survive. Customer or buyer must have access to product information round-the-clock and it should not be bound with business timings. Similarly in the case of institutions, now with the availability of information on the website student can access and can obtain information about the universities and their programs by just logging on to the net. They don't need to travel anymore or to call for getting information. There are two ways the institutions maintain their websites:

- Static website

- Online website

Static website only provides information about the University, its programs and other details about the commencement of programs. More advance to this technology, now institutions are not only concerned to simply provide information to students but also link their website with the local database server. Students while getting information may also send their request for admission and can register him/herself for admission to any specific program. With the help on online website, a student may interact directly with the admission coordinator and chat. In Pakistan, there are innumerable institutions, which still do not have their websites. Some of the institutions do have their website but either static or 
not updated. Very few institutions have WIS in its true spirit.

Information and knowledge sharing is one of the key activities of any educational institutions. Information is shared by using information technology tools and it is now essential to implement information technology to remain at par to international standards of sharing knowledge. On the one hand information is shared through printed materials which are a traditional and expensive way but now with the help of websites the same knowledge has become cheap and easily accessible to the reader or researcher within very less time from it has init iated from its author. Website implementation in any institution is a part of overall Educational Information Systems (EIS) where along with development of institution's website, other academic administrative matters are also computerized or automated. In the developed countries, it is very rare to physically visit the institution for getting information rather one can download all possible information from the institution's website. This trend is taking upward curve in the developing countries but it will still take many years to come upto that level. The information, whether of any kind and related to introducing faculties or programs, admission or registration, examination or results, research or publication, alumni or reunion, etc, is available for prospective and existing students and researchers. There are following benefits of sharing information using websites for educational institutions:

- Facilitates knowledge transfer

- Low cost access to information

- Quick and immediate access to information

- Remote access with no physical boundaries

- Curriculum development

- 24-hour availability of information

- Online registration facility as regular or distance students

- No physical excursion

- Huge database and information material available

- Prevents re-inventing the wheel (in the context of research)

- Facilitate decision-making and strategic planning

\section{WEBSITES IN THE HIGHER EDUCATIONAL INSTITUTIONS}

Higher Education Commission (HEC) is responsible to regulate, promote and find ways and means to take measures for quality education in Pakistan. After its restructuring from University Grants Commission (UGC) to HEC, it has further enhanced its control and supervision over the public and private institutions and compelling institutions to ensure true spirit of education without making it commercial business. It is appreciating to note that the HEC has also put its focus towards implementing information technology in these institutions. Within last 4 years special attention is given to improve the overall educational infrastructure and system but there is a steady progress in this regard.

If we take a brief overview of higher educational institutions having their own websites, almost all private institutions have their websites. It is further need to find out that whether these website are updated but as far its existence is concerned no one can deny its presence. On the other hand, if we look towards public institutions the positions is not much encouraging. Due to intervention of HEC, now it is mandatory for all public institutions to maintain their websites and also update them regularly.

\section{ESSENTIAL AND NON-ESSENTIAL INFORMATION FOR WEBSITES}

All information available on the websites is not necessary to be essential for everyone. Different people access the websites to fulfill their different requirements. For example, prospective students are looking for information related to admissions and subsequent program details, eligibility, fee structure, financial assistance, etc whereas a researcher may be looking for articles and publications on the institution's credit in order to get benefit. Mostly websites are accessed to get admissions and this is the reason almost all institutions put information related to admissions on their websites. Further, information about courses, academic calendar, examination results, etc are important for existing students. They also access their institution's websites to know what is happening new. Graduates of the institutions are least concerned about what mentioned above but they are more interested to know the database of their fellows and this is why many institutions have included alumni section in their websites. This facility gives an access to the passed out students to see the profiles of all students passed in a program in the specific years. It is important for institutions to know there website's target audience and design the infrastructure of website accordingly so everyone may access the information without going into the non-concerned area.

\section{FINDINGS}

It has been observed from the research that $79 \%$ of the public and $88 \%$ of the private institutions have their websites. This shows that there is not much difference as far as developing websites are concerned. In today's age of information technology we need to have websites ofour all institutions and the above percentage is not sufficient. Developing website is neither costly nor it requires very special human resource. As far as availability of information regarding faculty and staff is concerned, $83 \%$ of public whereas $75 \%$ of the private institutions have this information available on their websites. To access information from other then homepage, links from the home page is very essential. According to findings, $92 \%$ of the private whereas $83 \%$ of public institutions provide link to different pages from their institution website's homepage. $83 \%$ of the public and $92 \%$ of the private 
institutions' websites provide e-mail to contact them for further query.

Admission is one of the core activities of any educational institution, therefore $80 \%$ of the public and $92 \%$ of private institutions' website host this information for their prospective students. In the same connection, $76 \%$ of public and $81 \%$ of private institutions have specified admission application procedure including eligibility to get admissions to different programs. The study shows that $98 \%$ of the public and $94 \%$ of the private institutions have detail information about institutions' department and programs. Information regarding financial assistance, scholarship and concession is concerned only $15 \%$ of the public institutions have specified the criteria whereas this figure is little high at the private institution where $42 \%$ institutions' websites have this information. The reason for less percentage in public institutions' is that these institutions are already charging low fees. As far as online submission of admission application information is concerned only $15 \%$ of public and $14 \%$ of the private institutions offer this service to prospective students. This area needs to be ta ken care in order to facilitate students to apply for admission through websites. $54 \%$ of the public whereas $61 \%$ of the private institutions upload list of finally selected candidates after admission selection process. The research shows that $54 \%$ of the public and $53 \%$ of the private institutions' website have fee information.

The findings show that only $7 \%$ of public and $8 \%$ of private institutions have course outlines on their websites. No public institution offers online registration to students whereas only $8 \%$ of the private institutions give facility for online registration to existing students. $49 \%$ of public and $53 \%$ of private institutions upload semester results on their websites. Only $7 \%$ and $8 \%$ of the public and private institutions' websites have clas s schedule/time table respectively. $69 \%$ of the private institutions' websites host academic calendar whereas it is only $34 \%$ at the public institutions. Only $10 \%$ public institutions provide facility to its existing students to share information and knowledge with the teachers whereas this is $22 \%$ in the private institutions. Access to library and its books are concerned, $32 \%$ of public and $36 \%$ of the private institutions' websites provide link. $44 \%$ of private institutions' websites have research and publication whereas it is $37 \%$ with the public institutions.

The research shows that $42 \%$ private and $22 \%$ public institutions' websites have alumni information. $15 \%$ of the public and $22 \%$ of private institutions' websites host information regarding training \& develop ment programs. $46 \%$ of the public and $31 \%$ of the private institutions place vacant positions of their institutions on the websites.

\section{CONCLUSIONS \& RECOMMENDATIONS}

It is encouraging to note that good numbers of institutions are now having their own websites. Government must ensure that all public institutions should have their websites and made it compulsory for all private institutions chartered or registered by HEC to have their websites. There must be a specific website model that includes compulsory components to be incorporated in the educational institutions' websites. The model may be uploaded on the HEC's website. It has been observed from the study that educational websites as a whole lack online registration and submission of online application. The educational institutes must take measures to facilitate prospective students by providing them the facility of online submission of application forms and existing students by allowing them to register online for their forthcoming semesters or sessions. The institutions make it compulsory to upload admission test and examination results on the websites. At present, study shows that there are only $49 \%$ of the public and $53 \%$ of the private institutions upload semester or session results. It is recommended that all institutions must specify information about admission procedure, fee structure and fee concession as most of the prospective students are looking for this information. In today's competitive environment specially in Pakistan, job is an another issue which is ahead to those qualifying from different educational institutions. It is the responsibility of the institutions to establish a database of students in the 'alumni' section of the institution's website who are looking for jobs or better career prospects. The potential employers can access this database for the employment purposes. It is further observed that few educational institutions' websites are too loaded with images and take more than a minute to open. This loses the interest of the student and is not recommended. The appropriate time to open a homepage of a website is 20 to 30 seconds as most of the websites take this much time to display their homepage. It is good to observe that $46 \%$ of the public and $31 \%$ of the private institutions upload institutions' job vacancies on the website but it needs to improve more. There is lot to do in this regard but the immediate consideration is to bring all public and private institutions at one level for the sake of uniformity. The new initiatives may be to link the websites with foreign institutions' online training program, digitizing the library data and uploading on the websites and creating an online profile from where a student can see his or her academic records including results, registration, fee deposited, fees outstanding, etc. Linking the websites with foreign educational information resources can be a further valueaddition. In concluding, I would say that there should be a separate arm at HEC which should monitor the websites of all public and private institutions and keep suggesting ways and means to improve them and on the other hand students are encouraged to use website to access to information on net and to solve their day-to-day academic matters from institution's websites.

all results for them to upload academic calendar consider to has been concluded from the survey that government should take steps only $15 \%$ institutions have all core educational information systems applicable which is not 
very appreciating. The situation in private institutions is far better than that of government owned institutions where due to non-availability of information systems, results and registrations are delayed, students' records are maintained improperly and sorted manually. Due to noncomputerization, overall operational efficiency of academic administrative matters badly effects. Institutions have taken initiative and now moving towards implementing educational information systems in order to facilitate academic administrative matters. It has been found that computerization of academic administration is likely to be implemented if top management of the institutions take interest. Further, there is need of software houses, which may be specialized in developing educational information systems. There are hundreds of software houses but their concentration is more towards providing information systems solutions to business organizations. Most of the government educational institutions in particular and private in general are not-forprofit organizations where government has to take initiative to computerize the academic operations by providing free information system and hardware. It should be made mandatory for all institutions to have their websites, e-mail addresses and computer generated results and this to be monitored thoroughly. No institution has denied the importance of application of educational information system but lack of initiative, top management's interest, financial support and infrastructure are the major hurdles towards computerization in the educational institutions. In concluding, it shows that the inclination towards computerization is increasing and institutions without educational information systems will have no choice except to implement information system in order to bring overall efficiency in academic administrative matters that will have direct impact on the core academic matters of the institutions.

\section{REFERENCES}

[1] Muhammad Kamran Jamil (MKJ):Syed Asad Hussain (SAH); 2003; Application of Information System in the Education industry of Pakistan, SZABIST

[2] Steven Alter; 1998; Information Systems - A Management Perspective; The Benjamin/Cummings Publishing Company, Inc.; Singapore

[3] Muhammad Kamran Jamil (MKJ):Syed Asad Hussain (SAH); 2003; Significance of Sharing Information using Websites for Educational Institutions in Pakistan; SZABIST

[4] Parvaiz Naim Dr.; October 6, 2002; Time to Stand Up for Change; The Dawn Dawn; Karachi

[5] Khalid Mahmood; 1998; Information Technology in Libraries - "A Pakistani Perspective"; Pak Book Corporation; Lahore 
Journal of Independent Studies and Research (JISR)

Volume 2, Number 1, January 2004 